\title{
A new step aeration approach towards the improvement of nitrogen removal in a
}

\section{full scale Carrousel oxidation ditch}

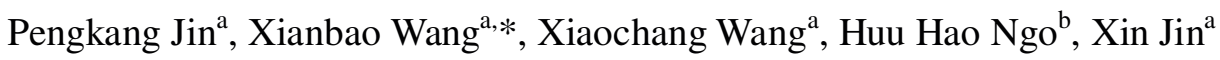

${ }^{\text {a }}$ School of Environmental and Municipal Engineering, Xi' an University of Architecture and Technology, Xi'an 710055, China

${ }^{\mathrm{b}}$ Centre for Technology in Water and Wastewater, School of Civil and Environmental Engineering, University of Technology Sydney, Sydney, NSW 2007, Australia

*Corresponding author, E-mail: wangxianbao1986@126.com, Tel. \& Fax.: (+86)2982205652

\begin{abstract}
Two aeration modes, step aeration and point aeration, were used in a full-scale Carrousel oxidation ditch with microporous aeration. The nitrogen removal performance and mechanism were analysed. With the same total aeration input, both aeration modes demonstrated good nitrification outcomes with the average efficiency in removing $\mathrm{NH}_{4}{ }^{+}-\mathrm{N}$ of more than $98 \%$. However, the average removal efficiencies for total nitrogen were $89.3 \%$ and $77.6 \%$ under step aeration and point aeration, respectively. The results indicated that an extended aerobic zone followed the aeration zones could affect the proportion of anoxic and oxic zones. The step aeration with larger anoxic zones indicated better TN removal efficiency. More importantly, step aeration provided the suitable environment for both nitrifiers and denitrifiers. The diversity and relative abundance of denitrifying bacteria under the step aeration $(1.55 \%)$ was higher than that under the point aeration $(1.12 \%)$, which resulted in an overall higher TN removal efficiency.
\end{abstract}


Keywords: Carrousel oxidation ditch; Nitrogen removal; Step aeration; Point aeration; Microbial community.

\section{Introduction}

The oxidation ditch (OD), as a modified activated sludge process, has been used for many years across the world, and nitrogen removal in an oxidation ditch has been a hot research subject for a long time. According to current theory, nitrogen removal in an oxidation ditch is achieved in the alternating anoxic-oxic zones by simultaneous nitrification and denitrification (SND) (Daigger et al., 2000; Ammary et al., 2005). Alternating anoxic-oxic zones can be formed within a channel by controlling the oxygen supply with surface aeration equipment (Liu et al., 1996; Liu et al., 2010), which was called point aeration in our previous study (Guo et al., 2013). Point aeration refers to aeration at several points of the oxidation ditch wherein several alternating anoxic-oxic zones are formed. The ideal scenario is that increasing nitrate through nitrification in the aerobic zones is equivalent to reducing nitrate by denitrification in the anoxic zones.

Therefore, the arrangement of the surface aeration equipment and control of dissolved oxygen (DO) are critical to improving how well the oxidation ditch process removes nitrogen (Saida et al., 2010).

It is, however, very difficult to control the dissolved oxygen concentration and anoxic-oxic zoning proportion accurately under point aeration. The more alternating anoxic-oxic zones that are present, the more difficult it is to control the dissolved oxygen and anoxic-oxic zoning proportion. Consequently, nitrogen removal efficiency has been found to be less than ideal for some oxidation ditch processes (Gao et al., 2006; Insel et al., 2003). It has been shown that nitrogen removal could be enhanced and that the influence of daily fluctuations in the influent on removing nitrogen could be 
overcome by optimizing the aeration conditions (Gao et al., 2006; Liu et al., 2013).

However, as water quality standards for wastewater treatment plants have become stricter with the added requirement to meet energy-saving demands, problems for surface aeration reactors such as low oxygen supply efficiency and high-energy consumption have become unavoidable. Therefore, the oxidation ditch process with microporous aeration has received increasing scientific attention. The effects of airflow rate and agitation on oxygen transfer efficiency have been studied in a pilot-scale ditch system with bubble membrane diffusers (Gillot et al., 2000; Stéphanie et al. 2007). Liu et al. (2010) set up a pilot-scale Carrousel oxidation ditch with microporous aeration and determined the optimal dissolved oxygen state for simultaneous nitrification and denitrification. Zhou et al. (2012) enhanced the removal of nitrogen in a full-scale Orbal oxidation ditch with microporous aeration by optimizing the oxygen supply. The use of microporous aeration in the oxidation ditch improved the oxygen transfer efficiency and reduced energy consumption. However, the microporous aeration zones were arranged on several points of the oxidation ditch, such as the surface aeration equipment, and thus, this process was essentially still considered to be point aeration. The demand for precise control of dissolved oxygen and anoxic-oxic zoning proportion to improve nitrogen removal cannot be ignored. Therefore, nitrogen removal must be enhanced with more suitable methods.

Based on the above-mentioned problem of point aeration in an oxidation ditch, a new step aeration approach was proposed to enhance nitrogen removal. Step aeration refers to continuous aeration in a section of the oxidation ditch by gathering the microporous aeration zones, and the oxidation ditch system includes one alternating anoxic-oxic zone. Aiming to improve nitrogen removal, this study established step aeration in a full-scale Carrousel oxidation ditch. The optimal anoxic-oxic zoning proportion under step 
aeration was ascertained for the Carrousel oxidation ditch with microporous aeration. In addition, the mechanism for high-performance nitrogen removal under step aeration was analysed by microbial community distribution. This study suggested a novel aeration mode for oxidation ditches with microporous aeration that can significantly enhance nitrogen removal.

\section{Materials and Methods}

\subsection{Wastewater treatment plant description}

The six-corridor Carrousel oxidation ditch process with a treatment capacity of 80000 $\mathrm{m}^{3} / \mathrm{d}$ was employed in a wastewater treatment plant in Kunming, China. Three group processes (A, B and C) were utilized with the same influent water quality and independent return sludge system. The width of corridor was $7 \mathrm{~m}$. The microporous aeration system was adopted in the Carrousel oxidation ditch, and the effective depth was $4.0 \mathrm{~m}$. The four corridors in oxidation ditch were full of diffuser discs, and the diffuser discs were divided into lots of parts by pipelines and valves. The area of each part was basically the same and a valve and gas flowmeter were installed for each part. The air flow of each part could be adjusted by the valve and gas flowmeter while the operation of each part was independent. The influent of the wastewater treatment plant was mixed and equally distributed to the three groups of oxidation ditch in distribution well. Therefore, the quality and quantity of the influent for three groups of oxidation ditch was identical, and during the experiment the influent quality was as follows: $\mathrm{BOD}_{5}=360 \pm 86 \mathrm{mg} / \mathrm{L}, \mathrm{COD}=620 \pm 240 \mathrm{mg} / \mathrm{L}, \mathrm{TN}=45.5 \pm 6.3 \mathrm{mg} / \mathrm{L}$, and $\mathrm{NH}_{4}{ }^{+}-\mathrm{N}=$ $25.1 \pm 4.1 \mathrm{mg} / \mathrm{L}$.

\subsection{Operating conditions}


In the Carrousel oxidation ditch, step aeration was adopted for group A (Fig. 1a), which involved a continuous aeration section in the oxidation ditch system, including one alternating anoxic-oxic zone. Point aeration was adopted for group B (Fig. 1b), which involved the four aeration zones in the oxidation ditch system, including four alternating anoxic-oxic zones. Only one blower was used for the two groups of oxidation ditch systems under different aeration modes, and the air flow of the each aeration area was identical by controlling the gas flowmeter and valve during the experiment. Therefore, the total aeration input of the oxidation ditch was approximately proportional to the area of aeration zones. The area of aeration zones was thus used to represent the total aeration input of the oxidation ditch system. By controlling the aeration zone area of the oxidation ditch, the total aeration input can be adjusted in the step aeration operation. The other operating parameters of the two groups were identical (hydraulic retention time $($ HRT $)=12 \mathrm{~h}$, sludge retention time $($ SRT $)=30 \pm 5 \mathrm{~d}$, sludge concentration $=5000 \pm 500 \mathrm{mg} / \mathrm{L}$, influent flow rate $=1110 \pm 10 \mathrm{~m}^{3} / \mathrm{h}$, excessive sludge flow rate $=200 \pm 30 \mathrm{~m}^{3} / \mathrm{d}$ and circulating sludge rate $=1000 \pm 10 \mathrm{~m}^{3} / \mathrm{h}$ ).

\subsection{Chemical analysis}

The soluble chemical oxygen demand (SCOD), total nitrogen (TN), ammonium, nitrate, and nitrite were analysed according to standard methods (APHA, 1998). The determination of the maximum specific ammonia-uptake rate (AUR) was the same as described in our previous publication (Guo et al., 2013).

The activity of denitrifying bacteria was evaluated based on the maximum specific denitrification rate. An aliquot of $1000 \mathrm{~mL}$ of biomass from the oxidation ditch was placed into a beaker $(1000 \mathrm{~mL})$ and kept at $20{ }^{\circ} \mathrm{C}$. Potassium nitrate was added to the beaker to obtain an initial nitrate concentration of $20 \mathrm{mg} / \mathrm{L}$. The initial COD was 300 
$\mathrm{mg} / \mathrm{L}$, which was obtained by adding sodium acetate. Eight samples were taken over time to determine the denitrification rate, which was based on the consumption of $\mathrm{NO}_{3}{ }^{-} \mathrm{N}$ (linear correlation coefficient $\mathrm{R}^{2}>0.98$ ).

2.4. Analysis of microbial community by high-throughput 454 pyrosequencing

Sludge samples of both aeration modes with the same proportion of anoxic and oxic zones were taken from the system for DNA extraction using the Power Soil DNA Isolation Kit (MO Biomedicals, USA). The above DNA mixture was pooled and amplified by PCR using primer 357F (5'-CCTACGGGAGGCAGCAG-3') and 926R (5'-CCGTCAATTCMTTTRAGT-3') (Shu et al., 2015) targeting the V3-V5 regions. 25 $\mathrm{ml}$ of the PCR mixture contained $2.5 \mu 1$ of $10 \times$ Ex Taq Buffer, $2 \mu 1$ of dNTP mixture, $16.50 \mu \mathrm{l}$ of sterilization ultrapure water, $1 \mu \mathrm{M}$ aliquots of each primer $(10 \mu \mathrm{M}), 0.125 \mu \mathrm{l}$ of ExTaq (TaKaRa, Dalian, China) and $2 \mu \mathrm{l}$ DNA ( $2 \mathrm{ng} / \mu \mathrm{l})$. The thermocycling steps were as follows: $93{ }^{\circ} \mathrm{C}$ for 3 min followed by 27 cycles at $94{ }^{\circ} \mathrm{C}$ for $30 \mathrm{~s}, 55^{\circ} \mathrm{C}$ for $45 \mathrm{~s}$, $72{ }^{\circ} \mathrm{C}$ for $1 \mathrm{~min}$ and a final extension step at $72{ }^{\circ} \mathrm{C}$ for $10 \mathrm{~min}$. The composition of the PCR products of the 16S rRNA gene's V3-V5 region was determined by pyrosequencing using the Roche 454 GS FLX+ Titanium sequencer.

\subsection{Statistical analysis}

Qiime software (Caporaso et al., 2010) was applied to remove sequences containing more than one ambiguous base ('N') and sequences with a single-base high repetition zone (homologous) $>8$. The sequences shorter than 200 bps or more than $1000 \mathrm{bps}$ were also removed. Chimera sequencing was performed using the uchime (Edgar et al., 2011) method in the Mothur software application. The "RDP Align" tool in RDP's Pyrosequencing Pipeline served to align the effective sequences. The table for Qiime 
Species Abundance and Distribution Map for Multi-sample Species was used as the OTU table. Clusters of the same OTU at the phylum and genus levels were constructed by adopting metastats (White et al., 2009) order in Mothur to analyse significant differences between groups. An evolutionary tree and abundant information were generated by applying MEGAN4 software (Huson et al., 2011).

\section{Results and discussion}

\subsection{Effects of aeration zones on nitrogen removal}

The stability of the Carrousel oxidation ditch to remove nitrogen under the step aeration mode with various aeration zones is shown in Fig. 2. When the aeration zones occupied 1/7-1/4 of the volume of the oxidation ditch (aeration area/oxidation ditch, $\mathrm{A} / \mathrm{O})$, the system demonstrated a high nitrification effect with the mean concentration of the effluent $\mathrm{NH}_{4}{ }^{+}-\mathrm{N}$ being less than $1 \mathrm{mg} / \mathrm{L}$. When the volume of the aeration zones was reduced, the TN removal effect was gradually enhanced. TN in the effluent decreased from $13.2 \mathrm{mg} / \mathrm{L}$ to $5.2 \mathrm{mg} / \mathrm{L}$. The corresponding removal efficiency increased from $71.1 \%$ to $88.9 \%$. Nitrite accumulation was not observed during the whole operation process. In addition, the COD concentration in the effluent was lower than $30 \mathrm{mg} / \mathrm{L}$, which indicated that the dissolved oxygen supply was enough to remove the $\mathrm{NH}_{4}{ }^{+}-\mathrm{N}$ and organic matter when the aeration zones accounted for $1 / 7$ of the volume of the oxidation ditch. As the anoxic zones increased, the TN removal effect was enhanced accordingly. Meanwhile, with the decrease of aeration zones, the consumption of the influent carbon source by aerobic microorganisms was further reduced. The utilization rate of the carbon source for denitrification was improved, and the TN removal efficiency was ultimately enhanced.

However, as the aeration zones in the oxidation ditch process fell to $1 / 8$ and $1 / 9$ of the 
total volume, the effluent $\mathrm{NH}_{4}{ }^{+}-\mathrm{N}$ concentration increased to $2.67 \mathrm{mg} / \mathrm{L}$ and $6.44 \mathrm{mg} / \mathrm{L}$, respectively, indicating that the $\mathrm{NH}_{4}{ }^{+}-\mathrm{N}$ cannot be completely oxidized because of the insufficient aeration input to the system. When the aeration zones occupied 1/4 and 1/5 of the volume of the oxidation ditch, the sludge volume index (SVI) was about $112 \pm 16$ $\mathrm{mL} / \mathrm{g}$ and $122 \pm 9 \mathrm{~mL} / \mathrm{g}$ respectively. The SVI gradually increased with decreasing the volume of aeration zones, the SVI was $136 \pm 17 \mathrm{~mL} / \mathrm{g}$ and $142 \pm 14 \mathrm{~mL} / \mathrm{g}$ when the A/O decreased to $1 / 6$ and $1 / 7$. The SVI increased to $170-180 \mathrm{~mL} / \mathrm{g}$ when the $\mathrm{A} / \mathrm{O}$ was $1 / 8$ and $1 / 9$. The microscopic examination of the sludge showed that there were many filamentous bacteria in the sludge, and the sludge was in a slight bulking state (Kim et al., 1998). This phenomenon was caused by excessive reproduction of filamentous bacteria due to the insufficient dissolved oxygen input (Guo et al., 2014).

\subsection{Effect of extended aerobic zones on anoxic-oxic zoning proportion}

Due to high flow velocity in the oxidation ditch process, the dissolved oxygen concentration could not be reduced to anoxic conditions ( $\mathrm{DO}<0.5 \mathrm{mg} / \mathrm{L}$ ) immediately in a short distance as occurred in the AAO process when the sewage flowed into the anoxic zone. There were extended aerobic zones that followed aeration zones, and the dissolved oxygen concentration was higher than $0.5 \mathrm{mg} / \mathrm{L}$. The length of the extended aerobic zones is mainly affected by the oxygen consumption rate of the activated sludge (the rate is obtained by adding together the oxygen consumption of nitrobacterium, the oxygen consumption rate of heterotrophic bacteria and the endogenous respiration rate of the sludge), the flow velocity of the oxidation ditch, and the dissolved oxygen concentration of the aeration section. As can be seen from Fig. 3a, the length of the extended aerobic zones was positively correlated with the dissolved oxygen concentration of the aeration zones. The length of the extended aerobic zones increased 
gradually with increasing dissolved oxygen concentration of aeration zones. When the dissolved oxygen concentration of the aeration zones was $2.0 \mathrm{mg} / \mathrm{L}$, the length of the extended aerobic zones was more than $20 \mathrm{~m}$. The dissolved oxygen of the aeration zones under point aeration was in the range of 1.0 to $1.5 \mathrm{mg} / \mathrm{L}$. Due to continuous aeration occurring in the step aeration, the dissolved oxygen at the end of the aeration zone was approximately $2-3 \mathrm{mg} / \mathrm{L}$. Therefore, the extended aerobic zones were the essential part of the aerobic zones of the oxidation ditch, and it had significant effects on the anoxic-oxic zoning proportion of the oxidation ditch. In the design of oxidation ditch with microporous aeration, more attention must be paid to the extended aerobic zones. However, the length was not proportional to the dissolved oxygen concentration. This is mainly because enhancing the aeration intensity to increase the dissolved oxygen concentration increased flow velocity at the end of the aeration zone, resulting in a further increase in the length of the extended aerobic zones.

The volume of the aerobic zones under point aeration with more frequent aeration was significantly larger than that under step aeration with the same area of aeration zones (the same aeration input). The aerobic zones occupied $28 \%$ and $20 \%$ of the total volume of the oxidation ditch under point and step aeration, respectively, when the aeration zones occupied $1 / 7$ of the volume of the oxidation ditch (Fig. 3b).

Consequently, the TN removal effect could be enhanced because the larger anoxic zones were present under step aeration.

As the length of the extended aerobic zones was affected by the dissolve oxygen and others factors, the anoxic-oxic zoning proportion of the oxidation ditch with microporous aeration was difficult to control. The more the extended aerobic zones are present, the more difficult to control the anoxic-oxic zoning proportion is. Only one extended aerobic zones was formed in step aeration so as it was easier to control the 
anoxic-oxic zoning proportion of oxidation ditch under step aeration mode.

\subsection{Performance of step aeration in nitrogen removal}

Fig. 4 shows the nitrogen removal under the two aeration modes when the aeration zones both took up $1 / 7$ of the volume of the oxidation ditch. A favourable nitrification effect was obtained under the two aeration modes, with $98.1 \%$ and $98.4 \%$ removal efficiencies for $\mathrm{NH}_{4}{ }^{+}-\mathrm{N}$. The mean concentrations of $\mathrm{NH}_{4}{ }^{+}-\mathrm{N}$ in the effluent were $0.53 \pm 0.11 \mathrm{mg} / \mathrm{L}$ and $0.42 \pm 0.09 \mathrm{mg} / \mathrm{L}$ under step aeration and point aeration, respectively. The TN removal efficiencies were $89.3 \%$ for step aeration and $77.6 \%$ for point aeration. The effluent TN under step aeration was approximately $5.3 \pm 0.56 \mathrm{mg} / \mathrm{L}$, which was less than that of $11.1 \pm 1.2 \mathrm{mg} / \mathrm{L}$ under point aeration (Fig. $4 \mathrm{~b}$ ). It is obvious that the TN removal efficiency under step aeration was higher than that under point aeration when the same aeration zones were employed.

According to the analysis on anoxic-oxic zoning proportion allocation of oxidation ditch under two aeration modes, it can be found that the volume of anoxic zones in step aeration mode was larger with the same area of aeration zones, which may be a reason for higher TN removal efficiency in step aeration mode. The aerobic zones under point aeration were reduced to $20 \%$ of the total volume of the oxidation ditch by decreasing the aeration zones. During three months of stable operation of the system under point aeration, the effluent $\mathrm{NH}_{4}{ }^{+}-\mathrm{N}$ concentration was $0.79 \pm 0.32 \mathrm{mg} / \mathrm{L}$, and the $\mathrm{TN}$ concentration decreased to $8.3 \pm 2.3 \mathrm{mg} / \mathrm{L}$. This finding demonstrates that $\mathrm{TN}$ removal efficiency can be improved by reducing the volume of the aerobic zones under point aeration. However, under the same proportion of anoxic and oxic zones, the $\mathrm{NH}_{4}{ }^{+}-\mathrm{N}$ and TN removal efficiencies under step aeration were still higher than those under point aeration. The AUR of activated sludge under step aeration and point aeration with the 
same proportion of anoxic and oxic zones were $1.81 \pm 0.13 \mathrm{mgNH}_{4}{ }^{+}-\mathrm{N} / \mathrm{gMLSS} \cdot \mathrm{h}$ and $1.64 \pm 0.15 \mathrm{mgNH}_{4}{ }^{+}-\mathrm{N} / \mathrm{gMLSS} \cdot \mathrm{h}$, respectively. This finding showed that the aeration zones gathered in the continuous section of the oxidation ditch under step aeration, resulting in a higher dissolved oxygen concentration, which proved to be beneficial to the growth of the nitrifying bacteria and improved the nitrification capacity.

The TN removal paths in the oxidation ditch process were ammonia stripping, assimilation, and nitrification-denitrification. However, ammonia stripping was assumed to be negligible because the $\mathrm{pH}$ of the mixed liquor in the ditch was usually below 7.5 (Peng et al., 2008; Tiranuntakul et al., 2005). The nitrogen mass balances in Table 1 were compared under both aeration modes with identical process parameters such as the proportion of anoxic and oxic zones, influent TN load, SRT, HRT and MLSS. An average of $18 \%$ of the influent TN was removed via assimilation in the form of waste sludge under both aeration modes. TN in the effluent occupied $11 \%(141 \mathrm{kgTN} / \mathrm{d})$ and $17 \%(221 \mathrm{kgTN} / \mathrm{d})$ of the influent TN under step aeration and point aeration, respectively. Denitrification was the dominant TN removal pathway under both aeration modes. Approximately $942 \mathrm{kgTN} / \mathrm{d}$ and $833 \mathrm{kgTN} / \mathrm{d}$ were removed by denitrification under step aeration and point aeration, respectively. It is obvious that more TN was removed via denitrification under step aeration than under point aeration. Therefore, with the same proportion of anoxic and oxic zones, step aeration was conducive to denitrification in the Carrousel oxidation ditch with microporous aeration.

\subsection{Microbial community distribution}

Pyrosequencing of the samples from the oxidation ditch under step and point aeration modes yielded 8144 and 9764 effective sequences reads, respectively. The number of sequences was comparable to that of a previous study (Feng et al., 2012). For the 
sequences determined from the pyrosequencing, 1588 and 1906 operational taxonomic units (OTUs) were identified at the 3\% cut-off for step aeration and point aeration, respectively. Fig. 5 shows the relative bacterial community abundances at the phylum level for both aeration modes. The phyla with relative abundances higher than $0.5 \%$ are presented. Proteobacteria, Chloroflexi and Bacteroidetes were the main bacteria in both systems, which is consistent with most reported research results (George et al., 2011; Zang et al., 2008; Trilok et al., 2014). The relative abundance of each species in the communities was influenced by the aeration mode. Table 2 shows the differences in microbial community structure at the phylum level under the two aeration modes. $\mathrm{P}$-value is an individual measure of the false positive rate and is a function of the observed sample results (a statistic) that is used for testing a statistical hypothesis. P-value analysis indicates that there were significant differences for a phylum of a microorganism under the two aeration modes when the $\mathrm{p}$-value was less than 0.05 . The varying analysis results of the microbial community at the phylum level indicated that there were significant differences in the microbial community structure of these three main bacteria and many other phyla. As the influent loading and sludge operation (including the hydraulic retention time, sludge retention time, excessive sludge rate and circulating sludge rate) of the two processes were identical, it can be speculated that the microbial community was influenced by the different aeration modes.

To further compare the microbial communities of the two samples under step aeration and point aeration, all-against-all comparison was conducted with the MEGAN software application. Proteobacteria was the most abundant phylum under both aeration modes, and Alphaproteobacteria was an important class in Proteobacteria. Fig. 6 shows the difference of Alphaproteobacteria on the different levels of biological classification under both aeration modes. The pie charts adjacent to the leaves of the tree indicate the 
relative abundance of microorganisms on the class, order, family and genus levels in the two samples. The ratio of red area to blue area in each pie represent the ratio of the relative abundance of the corresponding microorganisms under point aeration to that under step aeration. It can be seen from Fig. 6 that the effect of different aeration modes on microbial communities was greater at low levels of biological classification, especially at the genus level. Most genera exist both in step aeration and point aeration, but the relative abundance of many genera, such as Hyphomicrobium,

Prosthecomicrobium, Rhodobacter, etc, was quite different. Meanwhile, some genera, for example, Caulobacter, Fodinicurvata, Erythromicrobium, etc., appeared only in step aeration. Many other genera, such as Agromonas, Pseudochrobactrum, Pedomicrobium, etc., existed only in point aeration.

The species and relative abundances of denitrifying bacteria under the two aeration modes with the same proportion of anoxic and oxic zones are shown in Table 3. There were 14 and 8 genera for denitrifying bacteria under the step aeration and point aeration modes, respectively. Denitrifying bacterial species under step aeration were richer compared to point aeration. The relative abundance of denitrifying bacteria under step aeration and point aeration was $1.55 \%$ and $1.12 \%$, respectively. There were more denitrifying bacteria under step aeration than under point aeration. Thauera, Zoogloea and Hyphomicrobium were three main denitrifying bacteria under both aeration modes, accounting for more than $80 \%$ of the total denitrifying bacteria. The relative abundance of Thauera was the highest under both aeration modes, and the relative abundance of Thauera under step aeration was double that under point aeration. The higher relative abundance and diversity of denitrifying bacteria under step aeration led to higher denitrification activity. The maximum specific denitrification rates under step aeration and point aeration were $2.43 \pm 0.12 \mathrm{mgNO}_{3}{ }^{-} \mathrm{N} / \mathrm{gMLSS} \cdot \mathrm{h}$ and $2.01 \pm 0.14$ 
$\mathrm{mgNO}_{3}{ }^{-} \mathrm{N} / \mathrm{gMLSS} \cdot \mathrm{h}$, respectively. These results correspond to the $\mathrm{TN}$ removal efficiency of the two systems. This indicated that point aeration did not favour the enrichment of denitrifying bacteria, some of which cannot adapt to the frequently alternating anoxic-oxic environment. Consequently, they were eliminated, which compromised the denitrification process. In contrast, step aeration, in which anoxic zones gathered continuously with fewer anoxic-oxic alternating frequencies, benefitted and enhanced the enrichment and activity of denitrifying bacteria.

\section{Conclusions}

A new step aeration approach was proposed to enhance nitrogen removal in oxidation ditch. The advantage of step aeration is that the influence of extended aerobic zones on anoxic-oxic zoning proportion can be controlled and ideal zoning proportion in oxidation ditch can be achieved. Compared with the traditional point aeration, step aeration provided the suitable environment for nitrifying bacteria and denitrifying bacteria. The effects of frequent alternating anoxic-oxic environment under point aeration on microorganism activity were reduced. The diversity and relative abundance of denitrifying bacteria under step aeration was found to be higher to achieve better nitrogen removal efficiency.

\section{Acknowledgements}

The study was supported by the National Natural Science Foundation of China (No. 51178376), the National Water Pollution Control and Management Technology Major Projects (No. 2011ZX07302-001-06), the Program for Innovative Research Team in Shaanxi Province (PIRT) (No. 2013KCT-13) and the New Century Excellent Talents Award Program from Ministry of Education of China (No. NCET-12-1043). The 
sequencing service was provided by Personal Biotechnology Co., Ltd. Shanghai, China.

\section{References}

1. Ammary, B.Y., Radaideh, J.A., 2005. Simultaneous nitrification and denitrification in an oxidation ditch plant. Chem. Biochem. Eng. Q. 19(2), 207-212.

2. APHA, 1998. Standard Methods for the Examination of Water and Wastewater. American Public Health Association/American Water Works Association/Water Environment Federation. Washington, DC.

3. Caporaso, J.G., Kuczynski, J., 2010. QIIME allows analysis of high-throughput community sequencing data. Nat. Methods 7(5), 335-336.

4. Daigger, G.T., Littleton, H.X., 2000. Characterization of simultaneous nutrient removal in staged, closed-loop bioreactors. Water Environ. Res. 72(3), 330-339.

5. Edgar, R.C., Haas, B.J., Clemente, J.C., Quince, C., Knight, R., 2011. UCHIME improves sensitivity and speed of chimera detection. Bioinformatics 27(16), 2194-2200. 6. Feng, Q., Wang, Y.X., Wang, T.M., Zheng, H., Chu, L.B., Zhang, C., Chen, H.Z., Kong, X.Q., Xing, X.H., 2012. Effects of packing rates of cubic-shaped polyurethane foam carriers on the microbial community and the removal of organics and nitrogen in moving bed biofilm reactors. Bioresour. Technol. 117, 201-207.

7. Gao, S.Y., Peng, Y.Z., Wang, S.Y., Yan, J., 2006. Novel strategy of nitrogen removal from domestic wastewater using pilot Orbal oxidation ditch. J. Environ. Sci. 18(5), 833-839.

8. Guo, C.Z., Fu, W., Chen, X.M., Peng, D.C., Jin, P.K., 2013. Nitrogen-removal performance and community structure of nitrifying bacteria under different aeration modes in an oxidation ditch. Water Res. 47, 3845-3853.

9. Guo, J.H., Wang, S.Y., Wang, Z.W., Peng, Y.Z., 2014. Effects of feeding pattern and 
dissolved oxygen concentration on microbial morphology and community structure: The competition between floc-forming bacteria and filamentous bacteria. Journal of Water Process Engineering 1, 108-114.

10. GILLOT, S., HEDUIT, A., 2000. Effect of Air Flow Rate on Oxygen Transfer in an Oxidation Ditch Equipped with Fine Bubble Diffusers and Slow Speed Mixers. Water Res. 34(5), 1756-1762.

11. George, F.W., Park, H.D., Brad, E., Christopher, A.F., Craig, S.C., 2011. Fine-scale bacterial community dynamics and the taxa-time relationship within a full-scale activated sludge bioreactor. Water Res. 45, 5476-5488.

12. Huson, D.H., Mitra, S., Ruscheweyh, H.J., Weber, N., Schuster, S.C., 2011. Integrative analysis of environmental sequences using MEGAN 4. Genome Res. 21(9), $1552-1560$.

13. Insel, J., Russel, D., Beck, B., Vanrolleghem, P.A., 2003. Evaluation of nutrient removal performance for an ORBAL plant using the ASM2d model. Proc. Water Environ. Fed. 12, 263-279.

14. Liu, J.X., Van, G.J.W., Doddema, H.J., Wang, B.Z., 1996. Influence of the aeration brush on nitrogen removal in the oxidation ditch. Eur. Water Pollut. Control. 6(4), 25-30.

15. Liu, Y.C., Shi, H.C., Xia, L., Shi, H.M., Shen, T.G., Wang, Z.Q., Wang, G., Wang, Y.Z., 2010. Study of operational conditions of simultaneous nitrification and denitrification in a Carrousel oxidation ditch for domestic wastewater treatment. Bioresour. Technol. 101, 901-906.

16. Liu, Y.C., Shi, H.C., Wang, Z.Q., Fan, L., Shi, H.M., 2013. Approach to enhancing nitrogen removal performance with fluctuation of influent in an oxidation ditch system. Chem. Eng. J. 219, 520-526. 
17. Kim, Y.C., Pipes, Y.O., Chung, P.G., 1998. Control of activated sludge bulking by operating clarifiers in a series. Water Sci. Technol. 38, 8-9.

18. Peng, Y.Z., Hou, H.X., Wang, S.Y., 2008. Nitrogen and phosphorus removal in pilot-scale anaerobic-anoxic oxidation ditch system. J. Environ. Sci. 20(4), 398-403. 19. Saida, B.A., Latifa, H., Hayet, C., Hedi, D., 2010. Aeration management in an oxidation ditch. Desalination 252, 172-178.

20. Shu, D.T., He, Y.L., Yue, H., Wang, Q.Y., 2015. Microbial structures and community functions of anaerobic sludge in six full-scale wastewater treatment plants as revealed by 454 high-throughput pyrosequencing. Bioresour. Technol. 186, 163-172. 21. Stéphanie, V., Kate, S., Karim, E., Christian, F., Jens, M., 2007. Impact of agitation and aeration on hydraulics and oxygen transfer in an aeration ditch: Local and global measurements. Chem. Eng. Sci. 62, 2545-2555.

22. Tiranuntakul, M., Jegatheesan, V., Schneider, P.A., Fracchia, H.L., 2005.

Performance of an oxidation ditch retrofitted with a membrane bioreactor during the start-up. Desalination 183(1-3), 417-424.

23. Trilok, C.Y., Anshuman, A. Khardenavis, A.K., 2014. Shifts in microbial community in response to dissolved oxygen levels in activated sludge. Bioresour. Technol. 165, 257-264.

24. White, J.R., Nagarajan, N., Pop, M., 2009. Statistical methods for detecting differentially abundant features in clinical metagenomic samples. PLoS Comput. Biol. 5(4), e1000352.

25. Zang, K.S., Kurisu, F., Kasuga, I., Furumai, H., Yagi, O., 2008. Analysis of the phylogenetic diversity of estrone-degrading bacteria in activated sewage sludge using microautoradiography-fluorescence in situ hybridization. Syst. Appl. Microbiol. 31, 206-214. 
26. Zhou, X., Guo, X.S., Han, Y.P., Liu, J.X., Ren, J.C., Wang, Y., Guo, Y.T., 2012.

Enhancing nitrogen removal in an Orbal oxidation ditch by optimization of oxygen supply: practice in a full-scale municipal wastewater treatment plant. Bioproc. Biosyst. Eng. 35, 1097-1105. 


\section{Figure captions}

Fig. 1 Operation mode of Carrousel oxidation ditch: (a) step aeration and (b) point aeration.

Fig. 2 (a) $\mathrm{NH}_{4}{ }^{+}-\mathrm{N}, \mathrm{NO}_{3}{ }^{-}-\mathrm{N}$ and $\mathrm{NO}_{2}{ }^{-}-\mathrm{N}$ and (b) $\mathrm{TN}$ profiles of Carrousel oxidation ditch under step aeration with different aeration zones (aeration area/oxidation ditch, A/O).

Fig. 3 (a) Length of extended aerobic zones with different DO and (b) proportion of anoxic and oxic zones under two aeration modes with the same aeration input. Values are means \pm SD (error bars) for three replicates.

Fig. 4 (a) $\mathrm{NH}_{4}{ }^{+}-\mathrm{N}$ and (b) TN profiles under point aeration and step aeration with the same aeration zones.

Fig. 5 Bacterial community compositions at the phylum level revealed by 454-pyrosequencing.

Fig. 6 Sequences from step aeration and point aeration assigned to NCBI taxonomies with BLAST and MEGAN. (Pie charts indicate the relative abundance for each genus.

The ratio of red area to blue area in each pie represented the ratio of the relative abundance of the corresponding genus under point aeration to that under step aeration.) 


\section{Table 1}

Nitrogen mass balance in the Carrousel oxidation ditch under step and point aeration modes with the same proportion of anoxic and oxic zones

\begin{tabular}{lcc}
\hline TN removal paths & Step aeration & Point aeration \\
\hline The removal amount $(\mathrm{kgTN} / \mathrm{d})$ and percentage $(\%)$ by denitrification & $942(71 \%)$ & $833(65 \%)$ \\
The removal amount $(\mathrm{kgTN} / \mathrm{d})$ and percentage $(\%)$ by assimilation & $238(18 \%)$ & $231(18 \%)$ \\
The removal amount $(\mathrm{kgTN} / \mathrm{d})$ and percentage $(\%)$ by effluent & $141(11 \%)$ & $221(17 \%)$ \\
\hline
\end{tabular}




\section{Table2}

The differences in microbial community structure at the phylum level under two aeration modes

\begin{tabular}{llll}
\hline \multirow{2}{*}{ Taxonomy } & \multicolumn{2}{c}{ Percentage of sequences (\%) } & \multirow{2}{*}{-value } \\
\cline { 2 - 3 } & \multicolumn{2}{c}{ Point aeration } & \multicolumn{2}{c}{ Step aeration } & \\
\hline Proteobacteria & 23.863 & 24.963 & $0.047^{\mathrm{a}}$ \\
Chloroflexi & 21.200 & 17.890 & $0^{\mathrm{a}}$ \\
Bacteroidetes & 17.605 & 19.192 & $0.003^{\mathrm{a}}$ \\
Acidobacteria & 7.005 & 6.655 & 0.418 \\
Actinobacteria & 5.315 & 5.906 & 0.070 \\
Firmicutes & 2.438 & 2.468 & 0.846 \\
TM7 & 1.004 & 0.982 & 0.940 \\
Planctomycetes & 0.830 & 0.417 & $0.001^{\mathrm{a}}$ \\
Gemmatimonadetes & 0.492 & 0.516 & 0.832 \\
OP10 & 0.348 & 0.602 & $0.015^{\mathrm{a}}$ \\
Nitrospira & 0.369 & 0.196 & $0.037^{\mathrm{a}}$ \\
OP11 & 0.205 & 0.368 & $0.046^{\mathrm{a}}$ \\
Synergistetes & 0.051 & 0.061 & 0.763 \\
Verrucomicrobia & 0.051 & 0.098 & 0.274 \\
WS3 & 0.215 & 0.160 & 0.491 \\
Cyanobacteria & 0.031 & 0.061 & 0.481 \\
\hline
\end{tabular}

a: P-value is an individual measure of the false positive rate. It indicates that there are significant differences for a phylum of microorganism under the two aeration modes, when $\mathrm{p}$-value is less than 0.05 . 


\section{Table 3}

Species and relative abundances of denitrifying bacteria under the two aeration modes

\begin{tabular}{lll}
\hline \multirow{2}{*}{ Denitrifying bacteria } & \multicolumn{2}{l}{ Percentage of sequences (\%) } \\
\cline { 2 - 3 } & Point aeration & Step aeration \\
\hline Thauera & 0.328 & 0.724 \\
Hyphomicrobium & 0.358 & 0.246 \\
Zoogloea & 0.236 & 0.319 \\
Thiobacillus & 0.072 & 0 \\
Paracoccus & 0.061 & 0.012 \\
Methylobacter & 0.031 & 0.037 \\
Lactobacillus & 0.020 & 0.012 \\
Bacillus & 0.010 & 0.012 \\
Microbacterium & 0 & 0.049 \\
Comamonas & 0 & 0.037 \\
Eubacterium & 0 & 0.037 \\
Acinetobacter & 0 & 0.025 \\
Diaphorobacter & 0 & 0.012 \\
Flavobacterium & 0 & 0.012 \\
Stenotrophomonas & 0 & 0.012 \\
Total & 1.116 & 1.547 \\
\hline
\end{tabular}



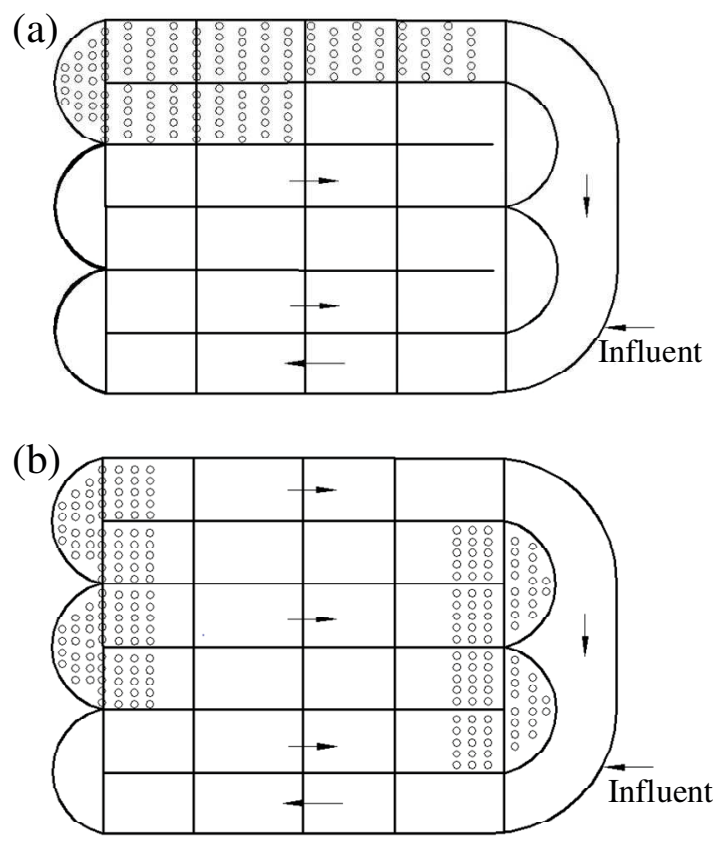

Fig. 1 
(a) - Influent $\mathrm{NH}_{4}{ }^{+} \mathrm{N} \quad \bullet$ Effluent $\mathrm{NH}_{4}{ }^{+}-\mathrm{N} \quad \Delta$ Effluent $\mathrm{NO}_{3}{ }^{-} \mathrm{N} \quad \diamond$ Effluent $\mathrm{NO}_{2}{ }^{-}-\mathrm{N}$
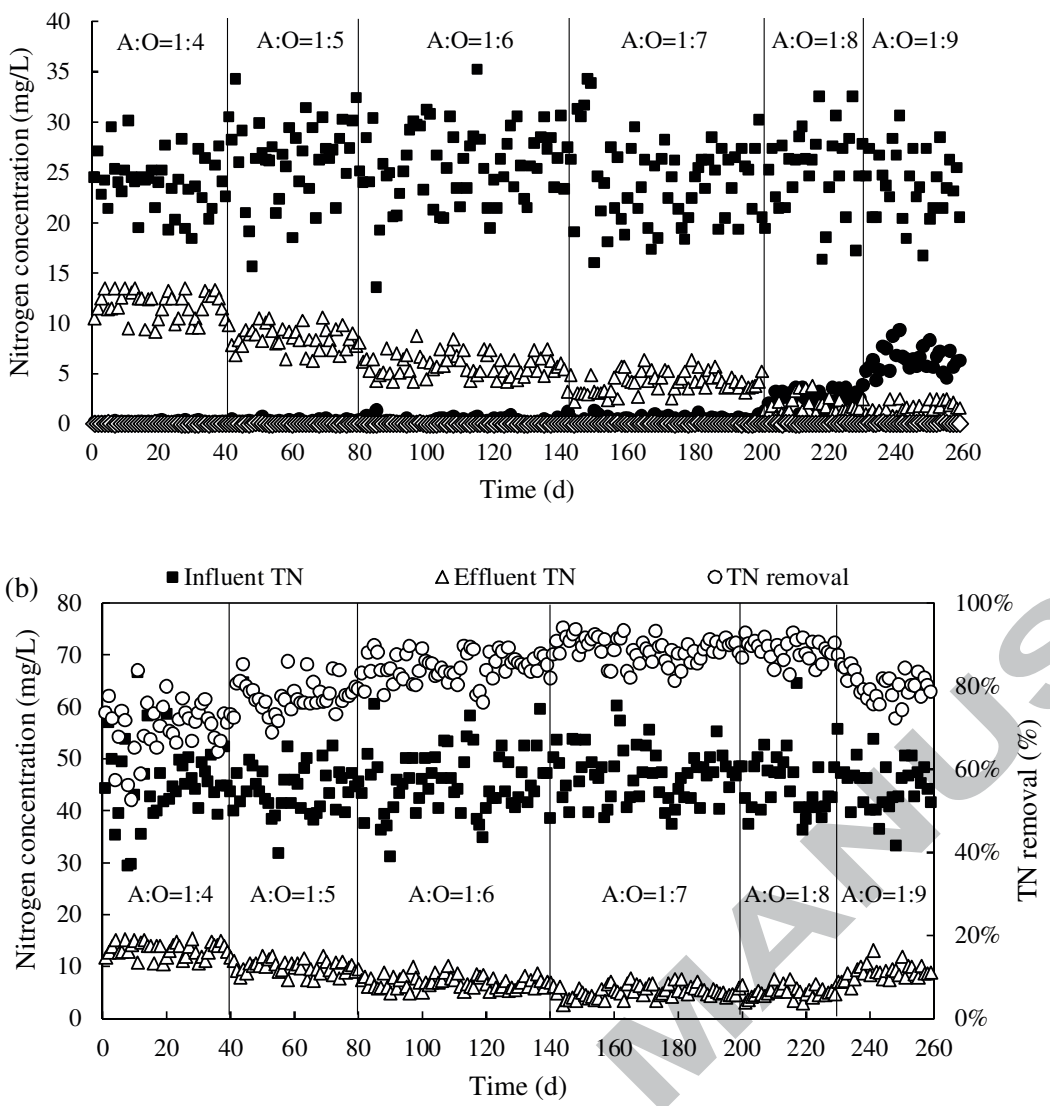

Fig. 2 


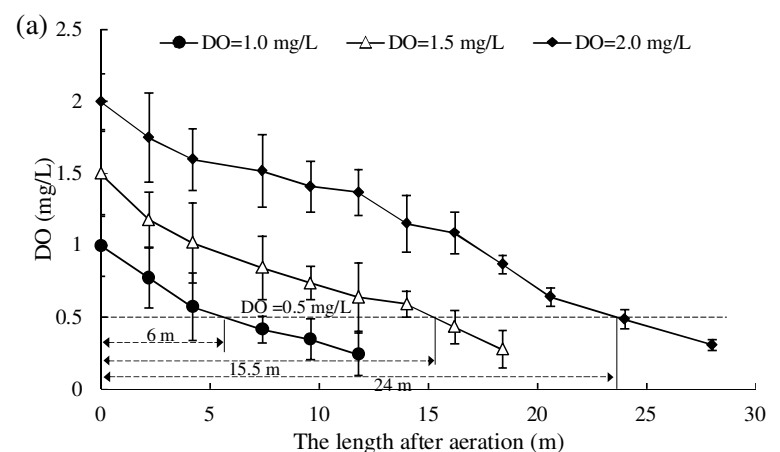

(b)
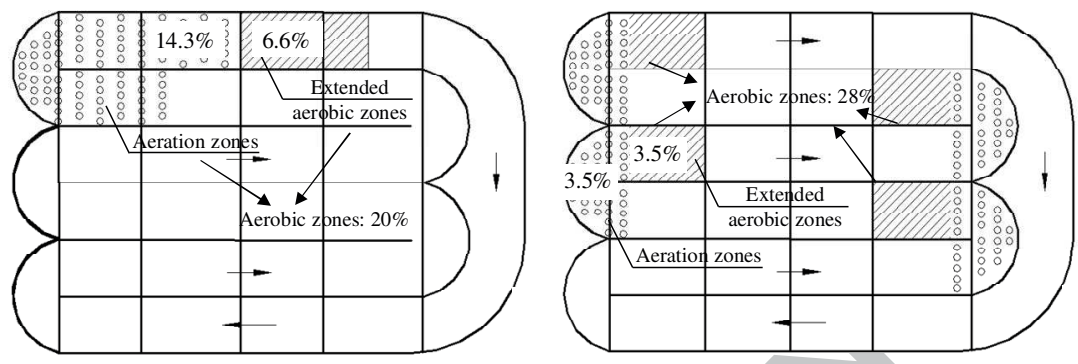

Fig. 3 

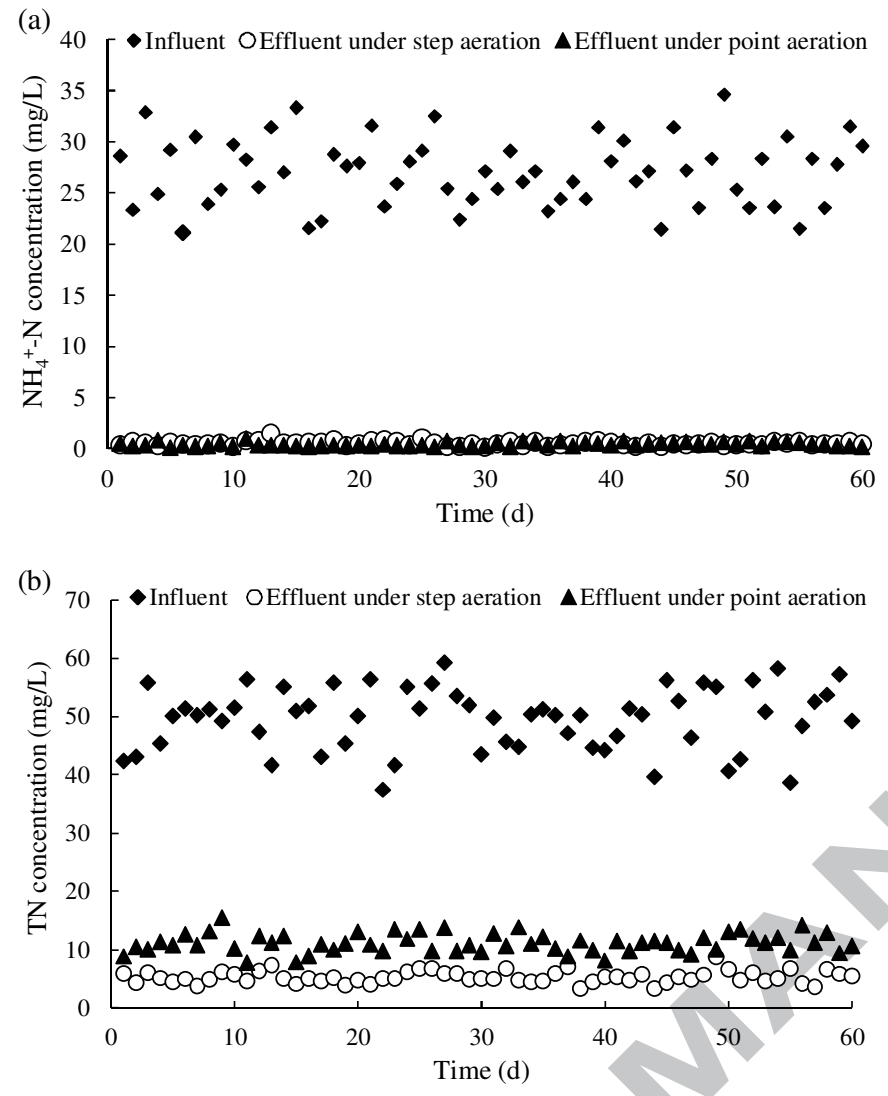

Fig. 4 


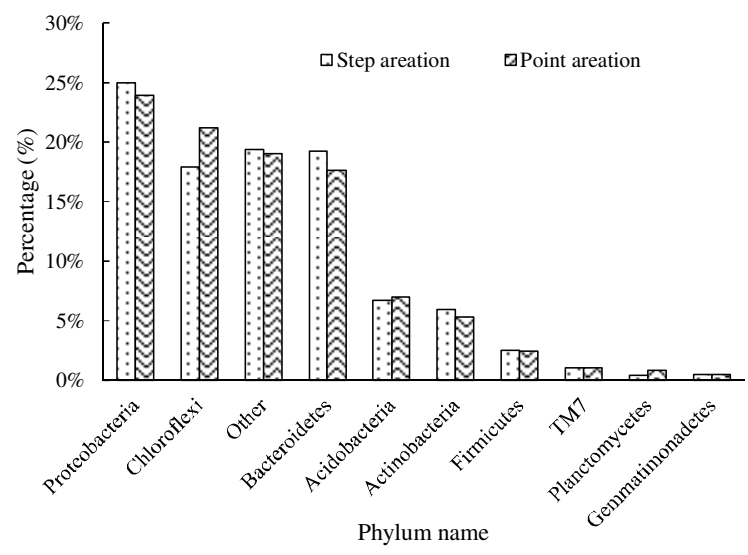

Fig. 5 

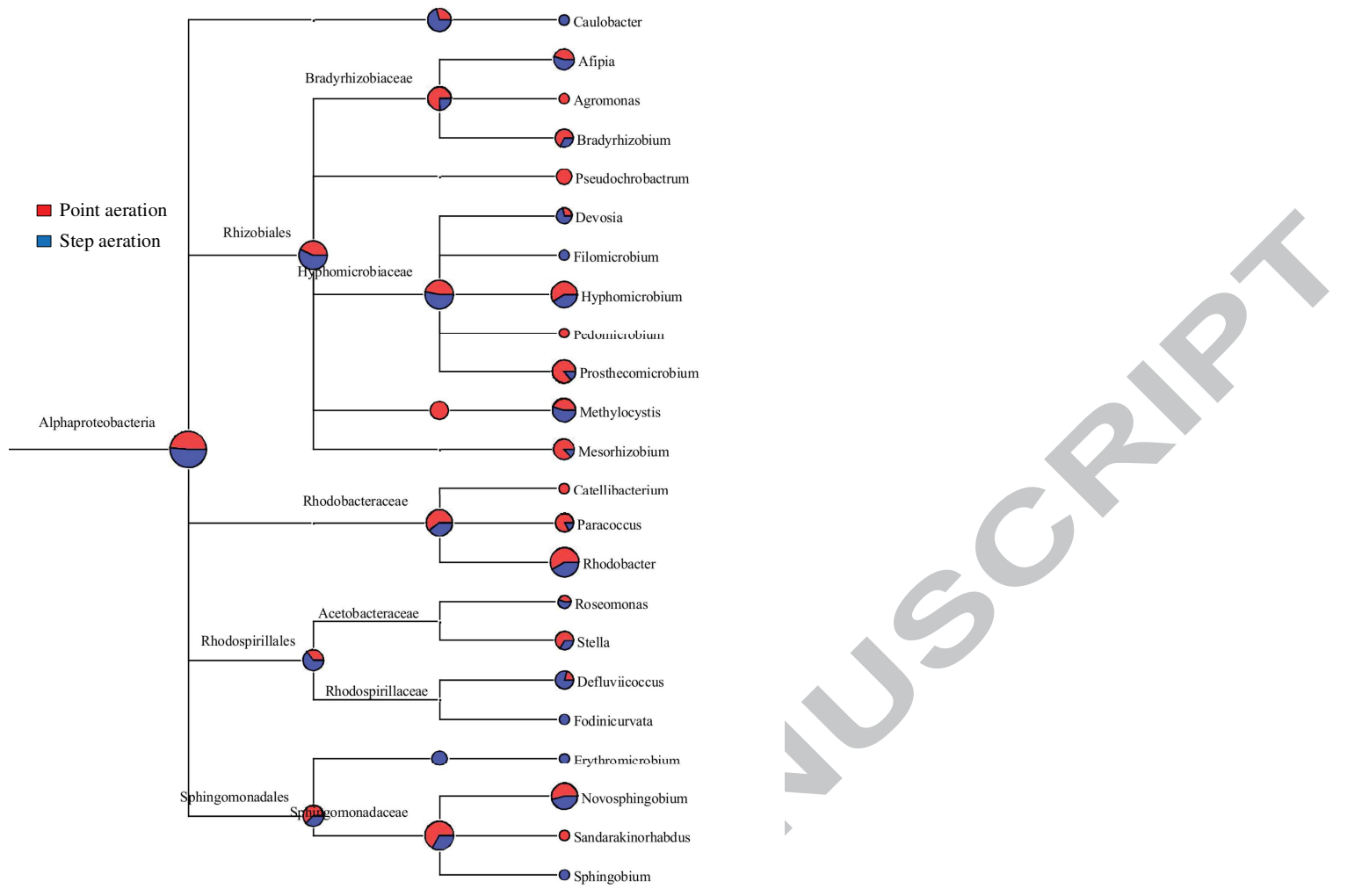

Fig. 6 

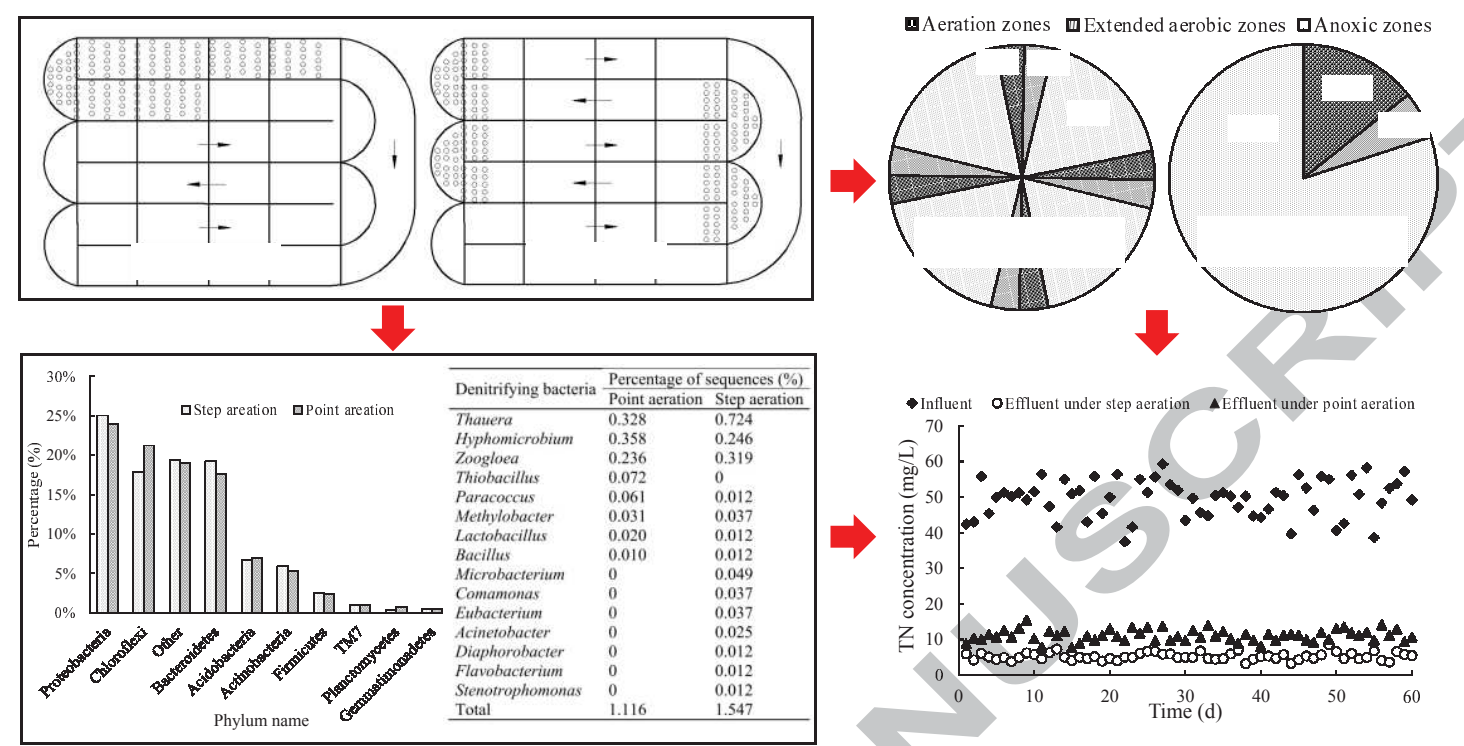


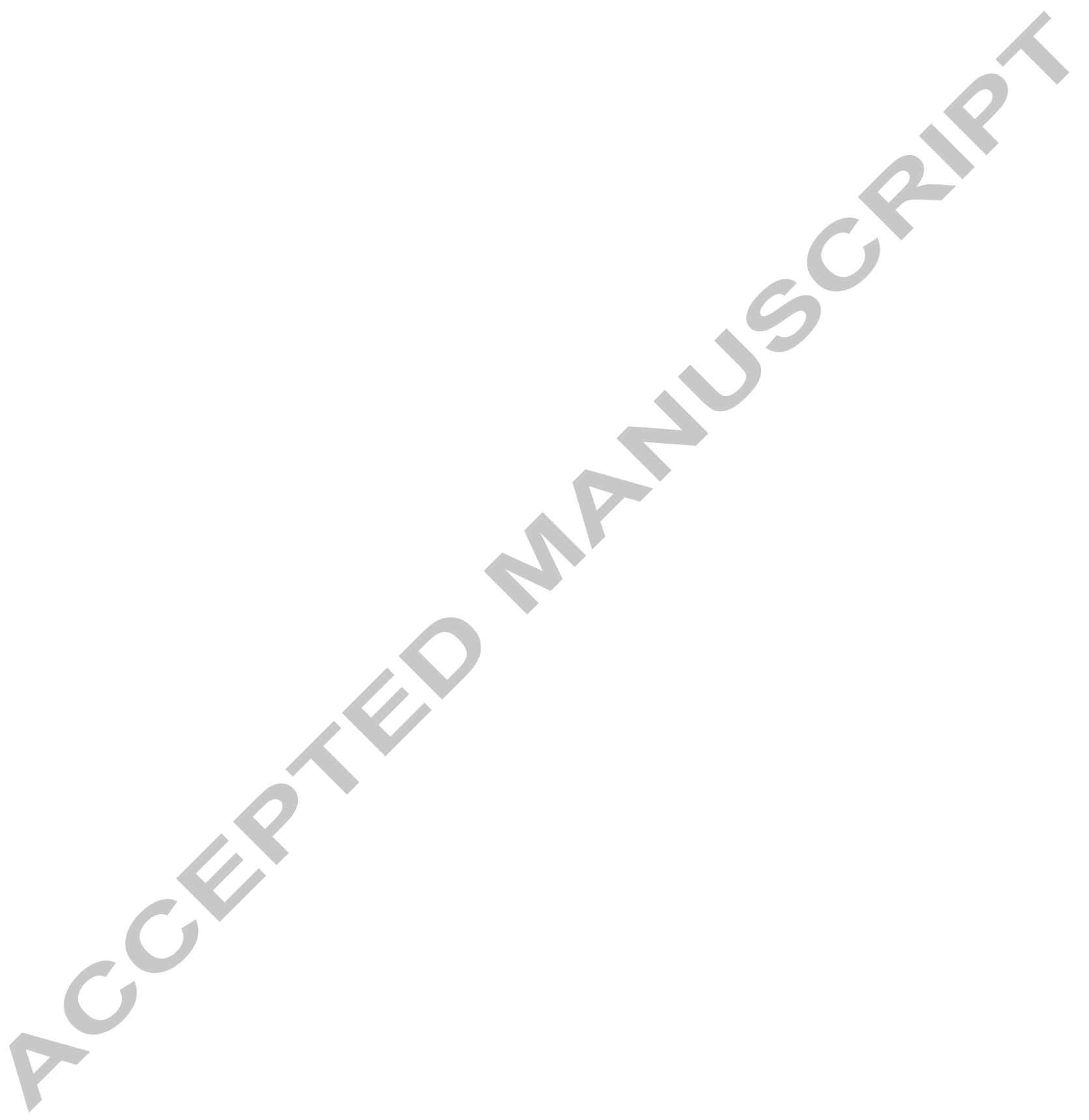

